\title{
Regular Econometric Model of Taylor for Albania
}

\author{
Av. Ergys Misha
}

Lawyer

\begin{abstract}
The Taylor's Rule Central Banks is applying widely today from Central Banks for design the monetary policy and for determination of interest rates. The purpose of this paper is to assess monetary policy rule in Albania, in view of an inflation targeting regime. In the first version of the Model, the Taylor's Rule assumes that base interest rate of the monetary policy varies depending on the change of (1) the inflation rate and (2) economic growth (Output Gap). Through this paper it is proposed changing the objective of the Bank of Albania by adding a new objective, that of "financial stability", along with the "price stability". This means that it is necessary to reassess the Taylor's Rule by modifying it with incorporation of indicators of financial stability. In the case of Albania, we consider that there is no regular market of financial assets in the absence of the Stock Exchange. For this reason, we will rely on the credit developmet - as a way to measure the financial cycle in the economy. In this case, the base rate of monetary policy will be changed throught: (1) Targeting Inflation Rate, (2) Nominal Targeting of Economic Growth, and (3) Targeting the Gap of the Ratio Credit/GDP (mitigating the boom cycle, if the gap is positive, and the contractiocycle if the gap is negative).The research data show that, it is necessary that the Bank of Albania should also include in its objective maintaining the financial stability. In this way, the contribution expected from the inclusion of credit gap indicators in Taylor's Rule, will be higher and sustainable in time. ${ }^{1}$
\end{abstract}

Keywords: Taylor Rule, Bank of Albania, Inflation targeting, Output gap, Credit gap.

\section{Introduction}

The literature suggest the Taylor's Rule to assess the monetary policy. Furthmore this Rule is applying widely today from Central Banks for design the monetary policy and for determination of interest rates.

According to Taylor (1993), monetary policy can be explained directly with a rule which link key interest rate of monetary policy with (1) deviation of inflation rate and (2) economic growth from their target level or potencial level respectively. With the proposal of this Rule, the monetary policy could quantify in a measurable way while also explaining the position of the Central Bank from macroeconomic shocks or from the fulfilling of their primary objective such as (1) inflation, or seconday as could be (2) economic growth.

The main instrument of the monetary policy in Albania is short term nominal interest rate. The Central Bank use this instrument (interest rate) to achieve the desired/targeted inflation rate. Evethough, it is suposed that the Central Bank react also to the output gap, although a lower persistent than in the case of the inflation gap.

In the case we assess the Rule of Taylor for the monetary policy, this imply that the interest rate is changed acoording to the deviation of targeted variables such as (1) Inflation and (2) Output, from their desired value.

\section{Methodology}

The evaluation of the Model will be done will OLS methodology (Ordinary Least Squares Method). This method estimates the linear relationship that exists between independent variables and the dependent ones. The dependent variable is the base interest rate of the monetary policy, while independent variables will be defined in terms of target's monetary policy respectively: Inflation targeting, by lowering the difference between actual and targeted inflation (desired) (3\%; closing

\footnotetext{
${ }^{1}$ (This paper is part of the theme "Achieving the price stability and maintain the financial stability, two main important objectives of the Central Banks" - from the study prepared for getting the scientific grade "Doctor of Economic Sciences" of the Author).
} 
of the Output Gap, defined as the difference between actual and potential output and, in the main proposal that constitutes the main contribution of this paper; closing the Credit Gap, that is the difference between actual and potential loan level. The last independent variable, ie the Credit Gap, is presented by this paper as an extension of the mandate of the Bank of Albania, to include also the financial stability.

\section{The main variables}

The purpose of this section is to estimate the monetary policy rule in Albania, in view of an inflation targeting regime.

The dependent variable is the base interest rate of the monetary policy (Interest Rate). Bank of Albania started to use indirect instruments of monetary policy in January 2001. The data used for Interest Rate are (1) the rate of refinancing of the Bank of Albania before this date, and (2) weekly repurchase agreement rates, in the coming period, and lie on a quarterly basis in the period 1998-2015. The source of data is the Bank of Albania.

The first independent variable is Inflation Rate and the its difference to the targeted inflation rate. Inflation rate is measured as the annual change in the Consumer Price Index, while targeted inflation rate is assumed to be $3 \%$, after the Bank of Albania has set the target inflation in the range of $3+/-1 \%$. The source of data is the Bank of Albania.

The second independent variable is Output Gap, which in the Model is measured as the difference between the actual level of GDP (gross domestic product) and its potential level. The data about GDP are reported by Institute of Statistics on a quarterly basis. To assess the level of potential GDP, is used HP filter (Hodrick Prescott), which serves to separate into the two components (long-term average and volatility on long-term average) the GDP indicator.

\section{Output Gap $=$ Gross Domestic Product - Potential Gross Domestic Product}

The third independent variable which will be used to assess the modified Taylor Rule is the Credit Gap, whose assessment will be presented below.

Evaluation of the Taylor rule with the usual method of Ordinary Least Squares, is made in the EViews program. The trend of indicators is presented graphically and identifies some periods.

REPO

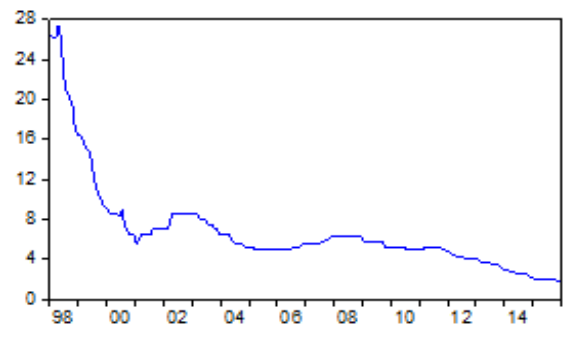

CREDIT_GAP

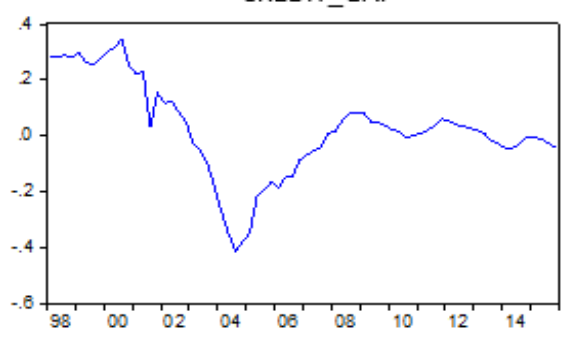

INF

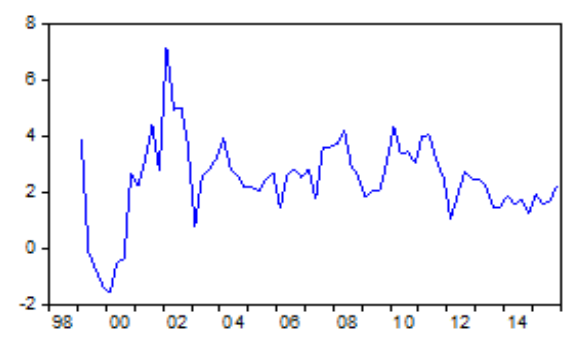

GDP_GAP

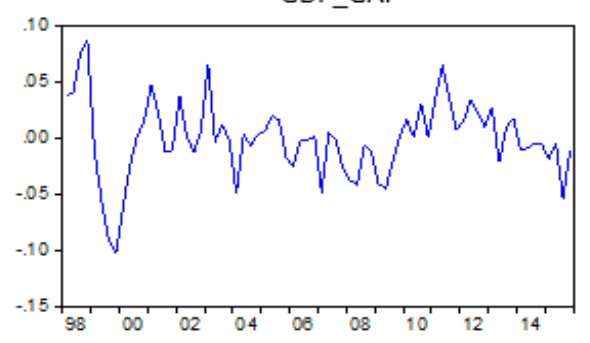

Repo rate shows some accommodative and tightening cycles of the monetary policy. Generally, up to 2002, the moment when the inflation grew, it is characterized by the reduction of the base interest rate. After that period, in order to reduce 
the inflation rate, tight monetary policy is impelemented until the end of 2004. Further, the reduction of inflation and of the positive output gap, is accompanied by a reduction in the base interest rate until the end of 2006. The beginning of 2007 marks a rapid growth of credit to the economy which passed over the potential level, along with the rapid expansion of the economy. Overheating of the economy in this period was accompanied by high inflation and tighter monetary policy accordingly. The end of 2008 marked the first cycle of accommodative monetary policy. The increase of inflation rate above the level of $3 \%$, record a brief period of tightening monetary policy. Meanwhile, starting from June 2011, the monetary policy has entered into its longer accomodative cycle, with consecutive cuts of base interest rate.

\section{Research Questions}

In the first version of the Model, the Taylor's Rule assumes that base interest rate of the monetary policy varies depending on the change of (1) the inflation rate and (2) economic growth. Research questions for this model are:

\section{- What is the relationship between the movement of base interest rate of monetary policy and inflation?}

- What is the relationship between the movement of base interest rate of monetary policy and the Output Gap?

Consequently, the first hypothesis is: The relative change of base interest rate of monetary policy depends on the relative difference in the inflation rate, economic growth and the sustainability of the base interest rate (coefficient $C(2)$ in Model).

To test the first hypothesis, following is the statistical presentation of the Taylor Rule Model, which aims to assess the relationship between Repo rate (dependend variable) and Inflation Rate (independed variable) and Output Gap (dependend variable):

$R=c(1)+c(2)^{*} R(-1)+c(3)^{*} \operatorname{lnf}+(1-c(3))^{*}(\inf (+4)-3)+c(4)^{*} \mathrm{GAP}(-1)$

Where: $\quad \mathbf{R}-$ is the base rate of the monetary policy

Inf - is annual inflation rate

$3 \%$ is the level of target inflation rate

Gap - is the difference between actual level of GDP and its potential level.

Coefficient $\mathbf{C}(1)$ is a constant which explains developments in the dependent variable which are not explained by the independent variables.

Coefficient $\mathbf{C ( 2 )}$ assesses the sustainability of the base interest rate. How much does it change from $1 \%$ increase of base rate of the previous quarter.

Coefficient $C(3)$ assesses the relationship between base interest rate and annual inflation rate. How much does it change from $1 \%$ increase of inflation rate. Meanwhile, the relationship between expected inflation (after one year) and the target level of $3 \%$, is estimated as 1 - coefficient $C(3)$ (1 minus coefficient $C(3)$ ).

Coefficient $\mathbf{C}(4)$ assesses the relationship between base interest rate and Output Gap. How much does it change from $1 \%$ increase of the difference between GDP and potencial level of GDP.

Model evaluation results are shown in Table 1

Table 1

\section{Evaluation of Taylor's Rule for Albania}

Dependent Variable: REPO

Method: Least Squares

Sample (adjusted): 1999Q1 2014Q4

Included observations: 64 after adjustments 


\begin{tabular}{lllll} 
& Coefficient & Std. Error & t-Statistic & Prob. \\
\hline \hline $\mathrm{C}(1)$ & -0.833762 & 0.263234 & -3.167376 & 0.0024 \\
$\mathrm{C}(2)$ & 0.944428 & 0.033816 & 27.92879 & 0.0000 \\
$\mathrm{C}(3)$ & 0.457651 & 0.044385 & 10.31101 & 0.0000 \\
$\mathrm{C}(4)$ & 0.064541 & 0.017136 & 3.766367 & 0.0004 \\
\hline \hline R-squared & 0.921573 & Mean dependent var & 6.096354 \\
Adjusted R-squared & 0.917652 & S.D. dependent var & 2.407029 \\
S.E. of regression & 0.690730 & Akaike info criterion & 2.158325 \\
Sum squared resid & 28.62645 & Schwarz criterion & 2.293255 \\
Log likelihood & -65.06640 & Hannan-Quinn criter. & 2.211481 \\
Durbin-Watson stat & 1.241635 & & \\
\hline \hline
\end{tabular}

The results of the Model suggest that there is a statistically significant relationship between the trend of the interest rate of monetary policy and developments of Inflation and the Output Gap. By replacing statistical model coefficients with corresponding values presented in Table 1, the Model presents as follows:

\section{$R=-0.83+0.94 R(-1)+0.45^{*}$ inf $+(1-0.45)^{\star}($ inf -3$)+0.06^{\star} \operatorname{GAP}(-1)$}

Coefficient $\mathbf{C}(\mathbf{1})$, which is a constant which explains developments in the dependent variable which are not explained by the independent variables, is assessed -0.83 .

Coefficient $\mathbf{C}(2)$ assesses the sustainability of the base interest rate and its level is high, 0.94 . This coefficient assess that the increase with 1 point percent of base interest rate in previous quarter, increase the actual base rate with 0.94 point percent, and this also supported by graphical presentation which shows that change of Repos is gradual and volatile in time.

Coefficient $C(3)$ assesses the relationship between base interest rate and annual inflation rate and its level is 0.45 . In this case, the increase with 1 point percent of inflation rate, increase the base rate with 0.45 point percent. From the other side, the increase of expected inflation (after one year) above the level of $3 \%$, increase the base rate with (1-0.45), so with 0.55 point peercent.

Coefficient $\mathbf{C ( 4 )}$ assesses the relationship between base interest rate and Output Gap and its level is low, 0.06 . This means that, the increase of economy with 1 point percent higher than its potencial level, increase the base interest rate of monetary policy with 0.06 point percent.

Model results show that the connection that exists between the rate of the previous quarter and the current interest rate of monetary policy is important. The coefficient of 0.94 is higher than the coefficient of Inflation 0.45 and from the coeffiecient of economy's increase 0. 06. Also, Bank of Albania react more in the case where the inflation is over the target level of $3 \%$, rather than in the case where the economy is increased over the potencial level and is overheating. The Model explain about $92 \%$ of changes in the base rate, because $\mathrm{R} 2=0.92$.

These results apply also to the case when the economy is falling and inflation is below the level of $3 \%$. In this case, the Bank of Albania react by reduce the base interest rate if it has reduced the base rate in the previous quarter, followed by a further reduction if inflation is below the target level of $3 \%$ level and economic growth below its potential level.

To measure the statistical significance of each coefficient of the model, we build main hypotheses and alternative ones, as follows:

Main Hypothese 1: There does not exist the relationship between the base rate of monetary policy and the rate of previous quarter:

\section{$C(2)=0$}


Alternative Hypothese 1: There is a statistically significant relationship between the base rate of monetary policy and the rate of previous quarter:

$C^{*}(2) \neq 0$

To assess the statistical significance of the coefficient, build statistics " $t$ " (presented in the respective column in Table 1).

$$
t=\frac{C *_{2}-C_{2}}{\operatorname{dev} . \operatorname{stand} . C *_{2}}
$$

If this value is above the level of 1.96 (that is a static indicator, which is not calculated), then the coefficient is statistically significant/important, the probability ( $p$-value) that the basic hypothesis is true is less than $10 \%$ (that is accepted error).

For Coefficient $\mathrm{C}(2)$, result that $\mathrm{t}_{\text {statistic }} \mathbf{\mathbf { 2 7 }} . \mathbf{9}$, and the propability of error $\mathbf{p}$-value $\mathbf{\mathbf { 0 }} \mathbf{\mathbf { 0 }} \mathbf{\mathbf { 0 0 }}$. In this case the basic hypothesis falls down and is accepted that alternative indicating that there is a statistically significant link between the base rate of the previous quarter and the current one.

Main Hypothese 2: There does not exist the statistic relationship between the base rate of monetary policy and the inflation rate:

$C(3)=0$

Alternative Hypothese 2: There is a statistically significant relationship between the base rate of monetary policy and the inflation rate:

$C(3) \neq 0$

For Coefficient $C(3)$, result that $t_{\text {statistic }} \mathbf{1 0 . 3}$, and the propability of error $\mathbf{p}$-value $\mathbf{0} \mathbf{0 . 0 0}$. In this case the basic hypothesis falls down and is accepted that alternative indicating that there is a statistically significant link between the base rate and the inflation rate.

Main Hypothese 3: There does not exist the statistic relationship between the base rate of monetary policy and the economic growth of previous quarter:

$C(4)=0$

Alternative Hypothese 3: There is a statistically significant relationship between the base rate of monetary policy and the economic growth of previous quarter inflation rate:

$C(4) \neq 0$

For Coefficient $\mathrm{C}(4)$, result that $\mathrm{t}_{\text {statistic }} \mathbf{\mathbf { 3 }} \mathbf{\mathbf { 3 }} \mathbf{7 6}$ and the propability of error $\mathbf{p}$-value $\mathbf{\mathbf { 0 }} \mathbf{\mathbf { 0 }} \mathbf{\mathbf { 0 0 }}$. In this case the basic hypothesis falls down and is accepted that alternative indicating that there is a statistically significant link between the base rate and the economic growth.

\section{Assessment of monetary policy rule including financial stability: Modified Taylor's Rule}

The estimated approach of Taylor's Rule as above, means that the Central Bank react through interest rate movement based on (1) Inflation Gap and (2) Output Gap, in accordance with the Bank of Albania objective to maintain price level stability.

\section{What is proposed?}

It is proposed changing the objective of the Bank of Albania by adding a new objective, that of "financial stability", along with the price stability.

The proposal to extend the objective of the Central Bank in terms of maintaining financial stability, means that it is necessary to reassess the Taylor's Rule by modifying it with incorporation of indicators of financial stability.

This paper proposes that the Central Bank should expand its objective, and presents a first assessment of the modified Taylor's Rule. 
To find a solution, the literature and practice of developed countries proposed several approaches to the measurement of financial stability, such as:

(1) Prices of financial assets

(2) Indicator of Credit development

(3) Etc..

In the case of Albania, we consider that there is no regular market of financial assets in the absence of the Stock Exchange For this reason, we will rely on the credit developmet - as a way to measure the financial cycle in the economy.

According to Minsky (1972) and Kindleberger (1978), periods of overheating or excess boom in credit, clearly tend to become a source for the emergence of the financial crisis.

The empirical findings of many authors (such as Alessi and Detken (2009), Borgy and the others (2009), Borio and Lowe (2002, 2004), Drehmann and the others (2010, 2011), and Schularick and Taylor (2012)), lead us to the conclusion that indicators of credit growth perform well as early warning signals by providing preliminary financial crisis signals.

Dell'Ariccia and others (2012) conclude that:

- $1 / 3$ (a third) increased in credit outstanding is followed by a finanical crise, and

- 3/5 are followed with a period of poor economic performance (measured by the difference between the growth of actual GDP with its potential level), for a period up to six years after the end of overheating period (boom period).

The empirical findings at the micro level, according to Mendoza and Terrones (2008), show that the capital adequacy ratio of the bank tends to decline during the credit boom period, but the determination and identification of the boom periods is tricky.

The Basel Committee for Banking Supervision (BCBS) has recommended the indicator of Credit Gap, measured as the deviation of the ratio of credit/GDP, versus the long-term trend for the measurement of the financial cycle and the boom periods of credit in the economy.

According to this recommendation:

Loan outstanding is measured as loans granted to individuals and businesses, including loan granted by nonbanks financial institutions and credits from abroad.

The Basel Committee further proposes that the long-term trend of the ratio of credit to GDP (loans/GDP) is calculated through the Hodrick - Prescott filter (HP).

The Method HP (Hodrick Prescott), or as it is known in the literature HP filter, decomposes the Credit time series, Ct (current loans outstanding) into two components:

- $\quad$ Long -term average $\left(C_{t}^{*}\right)$ ( $\left.\underline{R R \text { average }}\right)$ that can be interpreted as the potential level of the loan, and

- Growth component or fluctuations around the long-term average $\left(G_{t}\right)$ (growth rate):

$$
C_{t}=C_{t}^{*}+G_{t}
$$

This method is based on the assumption that growth component fluctuates around the long-term average with amplitude being flattened in time. Consequently, the average deviations of credit from potential loan level assumed to approach to zero in the long run period.

HP filter minimizes the variance of the long-term average by a given weight $\lambda$ for the variance of the second difference of the component of growth. This is expressed in the following function: 


$$
\operatorname{Min} L=\left\{\sum_{t=1}^{T} G_{t}^{2}+\lambda \sum_{t=2}^{T}(\Delta Y)\right\}
$$

Where the $\lambda$ penalizes the variance in growth component. A small amount of $\lambda$ forms a potential production that varies according to loan trend, while a high value of $\lambda$ reduces the loan trend elasticity from a short-term fluctuations. While $\lambda$ goes towards infinit, the long-term trend which is obtained from the filter HP, appear like a linear time series.

The value of $\lambda$ can be get according to desired flattening level of the final trend. Generally for quarterly data it choosen the value 1600 , and for annual data the value from 100 to 10. By their application it can be clearly seen that the higher the value of $\lambda$, the greater is the difference of the series of actual credit level to the series of its trend.

In normal conditions, for developed countries, the Basel Committee's recommendation is the application of a softening parameter of 400,000 . For less developed countries, which does not have a long time series of data on loan outstanding, it is recommended that the smoothing parameter of filter to be at 25,000 or even lower. The literature does not suggest an optimal level of this filter, so we used the basic assumption that for quarterly datas, the value is 1600 .

By using this approach, the chart below estimates the long-term trend of the ratio "credit/GDP" through several levels of smoothing parameter of HP filter (Hodrick Prescott), respectively with 1,600; 25,000 and 400,000.

As expected, due to the short time series of data on credit outstanding, the increase of smoothing parameter is associated with the evaluation of a long-term trend almost linear, without fluctuation.

For this reason, the case of Albania, as a least developed country and where there has not a long time series of data on loan outstanding, we recommend using traditional smoothing parameter for quarterly data, 1,600 respectively.

\section{Graphic 1. The ratio Loan/GDP and its potencial level assesed by HP Filter (Hodrick Prescott)}

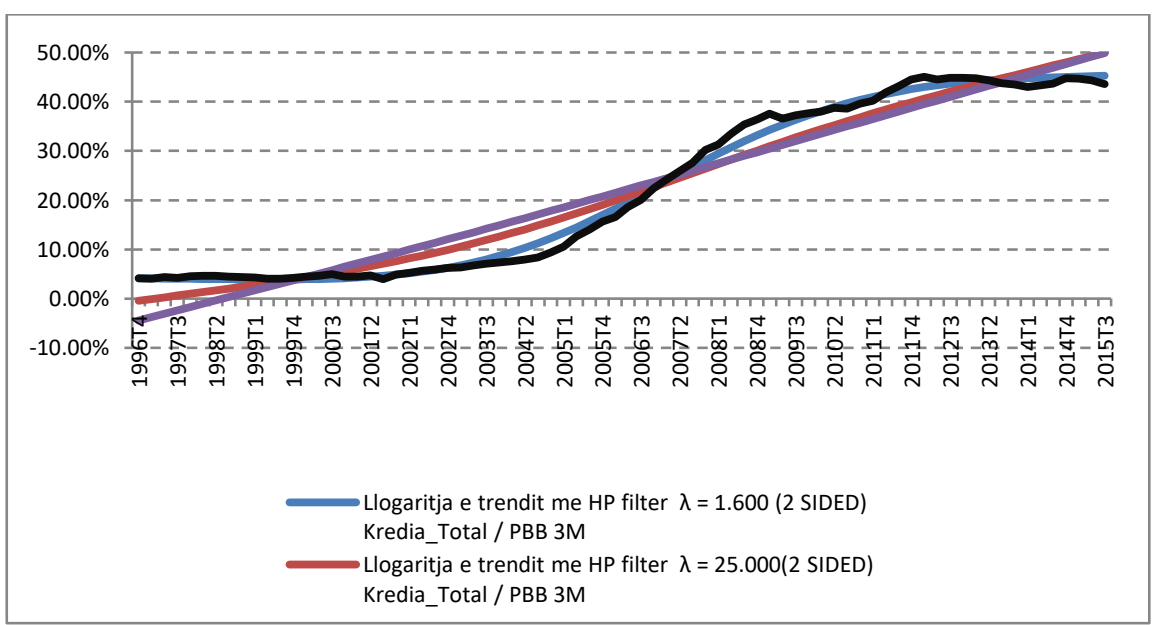

Proposing the use of the gap between the ratio "Credit/GDP" and the its potencial level, assessed through the HP filter at a smoothing rate of 1,600 quaterly terms, we assesed the Taylor's Rule might be, if the Bank of Albania includes in its objective also the financial stability.

In this case, the base rate of monetary policy will be changed throught:

1. Targeting Inflation Rate;

2. Nominal Targeting of Economic Growth, and 
3. Targeting the Gap of the Ratio Credit/GDP (mitigating the boom cycle, if the gap is positive, and the contractiocycle if the gap is negative).

The Research questions for the new model of the Taylor' Rule are:

- What is the relationship between the trend of base rate of monetary policy and trend of inflation?

- What is the relationship between the trend of base rate of monetary policy and Output Gap?

- What is the relationship between the trend of base rate of monetary policy and Credit Growth?

The model is built through the method of Ordinary Least Squares, which assumes a linear relationship between the dependent variable and independent ones.

The dependent variable of the Model is the base rate of the monetary policy of the Bank of Albania

The first independent variable of the Model is the difference of inflation rate from its target level of $3 \%$.

The second independent variable of the Model is the Output Gap.

The third independent variable of the Model which assesses precisely the proposal to include the financial stability in the objective of the Bank of Albania, measured as Credit Gap. This gap has the same valuation methodology as the Output Gap, is

\section{Credit Gap $=$ Credit Stock - Potencial Credit Stock}

The second hypothesis: Central Bank takes into account also the changes of credit level from its potential level, in the evaluation of monetary policy. In this case, the relative change in inflation, economic growth and credit growth, affect the relative change of base rate of monetary policy.

The statistical presentation of the Modified Model of Taylor's Rule is given as follows:

$R=c(1)^{*} R(-1)+c(2)^{*} \operatorname{lnf}+(1-c(2))^{*}(\inf (+4)-3)+c(3)^{*} G A P+$ dummy ${ }^{*} c(4)^{*} c r e d i t$ gap $(+3)$

Where: $\quad \mathbf{R}$ - is the rate of monetary policy

Inf - is the annual inflation rate

$3 \%$ - is the target level of inflation

Gap - is the difference between actual level og GDP and its potencial level Credit_gap - is the difference between teh ratios Credit/GDP and its potencial level

dummy - It is a qualitative variable that takes the value 0 before starting the accomodative cycle of monetary policy (QE), and 1 after the start of the cycle. Accomodative cycle of Monetary policy started in June 2011.

Coefficient $\mathbf{C ( 1 )}$ assesses the sustainability of the base interest rate. How much does it change from $1 \%$ increase of base rate of the previous quarter.

Coefficient $\mathbf{C ( 2 )}$ assesses the relationship between base interest rate and annual inflation rate. How much does it change from $1 \%$ increase of inflation rate. Meanwhile, the relationship between expected inflation (after one year) and the target level of $3 \%$, is estimated as 1 - coefficient $C(2)$ (1 minus coefficient $C(2)$ ).

Coefficient $C(3)$ assesses the relationship between base interest rate and Output Gap. How much does it change from $1 \%$ increase of the difference between GDP and potencial level of GDP.

Coefficient $\mathbf{C}(\mathbf{4})$ assesses the relationship between base interest rate and Credit Gap. How much does it change from $1 \%$ increase of the difference between Actual level of Credit and its potencial level. 
We expect the Central Bank to increase the interest rate if the credit is growing rapidly and the pozitive gap is expanded. In contrast, the Central Bank will decrease interest rate if the credit outstanding is slowing and the negativ gap to potential level, is expanded rapidly.

The results of the Model of Modified Taylor's Rule are presented in the Table 2.

\section{Table 2. The Assessment of Taylor's Rule for Albania}

\section{Dependent Variable: REPO}

Method: Least Squares (Gauss-Newton / Marquardt steps)

Sample (adjusted): 1999Q1 2014Q4

Included observations: 64 after adjustments

\begin{tabular}{lllll} 
& Coefficient & Std. Error & t-Statistic & Prob. \\
\hline \hline $\mathrm{C}(1)$ & 0.962402 & 0.013640 & 70.55647 & 0.0000 \\
$\mathrm{C}(2)$ & 0.425026 & 0.045133 & 9.417117 & 0.0000 \\
$\mathrm{C}(3)$ & 0.078790 & 0.025660 & 3.070536 & 0.0032 \\
$\mathrm{C}(4)$ & 0.189936 & 0.086042 & 2.207476 & 0.0311 \\
\hline \hline R-squared & 0.922722 & Mean dependent var & 6.096354 \\
Adjusted R-squared & 0.918858 & S.D. dependent var & 2.407029 \\
S.E. of regression & 0.685652 & Akaike info criterion & 2.143567 \\
Sum squared resid & 28.20709 & Schwarz criterion & 2.278498 \\
Log likelihood & -64.59415 & Hannan-Quinn criter. & 2.196723 \\
Durbin-Watson stat & 1.239983 & & \\
\hline \hline
\end{tabular}

Model results suggest that there is a statistically significant relationship between the trend of the base interest rate of monetary policy and developments in terms of inflation and the output gap. Replacing statistical model coefficients with corresponding values in the Table, the Model is presented as follows:

\section{$R=0.96^{*} R(-1)+0.42^{*} \inf +(1-0.42)^{*}(\inf (+4)-3)+0.07^{*} \mathrm{GAP}(-1)+0.18^{*}$ Credit_gap}

Coefficient $\mathbf{C}(\mathbf{1})$ assesses the sustainability of the base interest rate and its level is 0.96 , decreasing slightly compared to the first model. This coefficient assess that the increase with 1 point percent of base interest rate in previous quarter, increase the actual base rate with 0.96 point percent.

Coefficient $\mathbf{C}(\mathbf{2})$ assesses the relationship between base interest rate and annual inflation rate and its level 0.42 . In this case, the increase with 1 point percent of inflation rate of $3 \%$, increase the base rate with 0.42 point percent. From the other side, the increase of expected inflation (after one year) above the level of $3 \%$, increase the base rate with (1-0.42), so with 0.58 point peercent.

Coefficient $\mathbf{C ( 3 )}$ assesses the relationship between base interest rate and Output Gap and its level is low, 0.07 . This means that, the increase of economy with 1 point percent higher than its potencial level, increase the base interest rate of monetary policy with 0.07 point percent.

Last, Coefficient $\mathbf{C}(4)$ assesses the relationship between base interest rate and Expected Credit Gap and its level is low, 0.18 . This means that, the expected credit increase with 1 point percent higher than its potencial level, increase the base interest rate of monetary policy with 0.18 point percent.

The Model's results indicate that the connection exists between the rate of the previous quarter and the current interest rate of monetary policy remains important in the modified rule. The coefficient of 0.96 is higher than the coefficient of inflation 0.42 and the coefficient of economic growth, 0.07 . Also, the Bank of Albania react more if the inflation has passed the target level of $3 \%$, compared with the case when the economy is overheating and is growing above the potencial level. While the current model shows that actual credit growth is not statistically significant, but its expected growth (+ 3 quarterly). $\underline{\text { So, the Central Bank increase by } 0.18 \text { percentage points its base rate, if its forecasts indicate that credit will grow beyond }}$ 
the potential level after 3 quarters. The Dummy variable shows that the relationship between the Credit and the base rate is important after the start of the accommodative cycle of monetary policy.

These results apply also to the case when the economy is falling and the inflation is below the level of $3 \%$. In this case, the Bank of Albania react by decreasing the base rate if it has reduced it in the previous quarter, followed by a further reduction if inflation is below the level of $3 \%$, the economic growth is below the potential level, and credit is shrinked.

To measure the statistical significance of each coefficient of the Model, we build main hypotheses and alternative ones, as follows:

Main Hypothese 1: There does not exist the statistic relationship between the base rate of monetary policy and the previous quarterly rate:

$C(1)=0$

Alternative Hypothese 1: There is a statistically significant relationship between the base rate of monetary policy and the the previous quarterly rate:

$C^{*}(1) \neq 0$

To assess the statistical significance of the coefficient, build statistics " $t$ " (presented in the respective column in the Table).

$$
\boldsymbol{t}=\frac{\mathrm{C} *_{2}-C_{2}}{\operatorname{dev} . \text { stand. } C *_{2}}
$$

If this value is above 1.96 (that is a static indicator, which is not calculated), then the coefficient is statistically significant/important, the probability ( $\mathrm{p}$-value) that the basic hypothesis is true is less than $10 \%$ (that is accepted error).

For Coefficient $\mathrm{C}(2)$, result that $\mathrm{t}_{\text {statistik }} \mathbf{\mathbf { 7 0 . 5 }}$, and the propability of error $\mathbf{p}$-value $\mathbf{\mathbf { 0 }} \mathbf{0 . 0 0}$. In this case the basic hypothesis falls down and is accepted that alternative indicating that there is a statistically significant link between the base rate of the previous quarter and the current one.

Main Hypothese 2: There does not exist the statistic relationship between the base rate of monetary policy and the inflation rate:

$C(2)=0$

Alternative Hypothese 2: There is a statistically significant relationship between the base rate of monetary policy and the inflation rate:

$\mathrm{C}(2) \neq 0$

For Coefficient $C(3)$, result that $t_{\text {statistik }}=\mathbf{9 . 4}$, and the propability of error $\mathbf{p}$-value $\mathbf{= 0 . 0 0}$. In this case the basic hypothesis falls down and is accepted that alternative indicating that there is a statistically significant link between the base rate and the inflation rate.

Main Hypothese 3: There does not exist the statistic relationship between the base rate of monetary policy and the economic growth of previous quarter:

$C(3)=0$

Alternative Hypothese 3: There is a statistically significant relationship between the base rate of monetary policy and the economic growth of previous quarter inflation rate:

$\mathrm{C}(3) \neq 0$

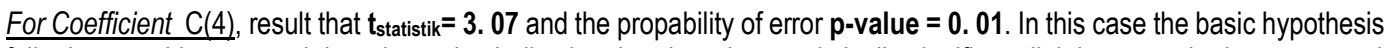
falls down and is accepted that alternative indicating that there is a statistically significant link between the base rate and the economic growth. 
Main Hypothese 4: There does not exist the statistic relationship between the base rate of monetary policy and the Credit Growth:

$C(4)=0$

Alternative Hypothese 4: There is a statistically significant relationship between the base rate of monetary policy and the Credit Growth:

$\mathrm{C}(4) \neq 0$

For Coefficient $\mathrm{C}(4)$, result that $\mathrm{t}_{\text {statistik }} \mathbf{=} \mathbf{2 . 2}$ and the propability of error $\mathbf{p}$-value $\mathbf{= 0 . 0 3}$. In this case the basic hypothesis falls down and is accepted that alternative indicating that there is a statistically significant link between the base rate and the expected credit growth.

\section{CONCLUSION}

In actual situation when the Bank of Albania has not included explicitly in its objective the financial stability, the directly reaction of interest rate based on credit gap is assessed as low taking into account the entire period.

For this reason, the Credit gap appears with a statisticaly importance after 2011.

What is expected and estimated in the Model is that the Bank of Albania can and should indirectly involved in its reaction to the base interest rate the credit development, through the output gap. Overall, economic growth in Albania is financed through loans, the main source of external financing for businesses and for consumers. In this case, a negative output gap following generally negative developments in credit terms. During 2015, for example, noted that the positive development of economic growth is not accompanied by a similar trend of credit expansion.

For this reason, it is necessary and that the Bank of Albania should also include in its objective maintaining the financial stability. In this way, the contribution expected from the inclusion of credit gap indicators in Taylor's Rule, will be higher and sustainable in time.

\section{Literature:}

[1] Minsky, HP (1972), "Financial Instability Revisited: The Economics of Disaster." Reappraisal of the Federal Reserve Discount Mechanism 3 (1972): 97-136.

[2] Kindleberger, CP (1978), Manias, Panics and Crashes: A History of Financial Crises, 1-st edition, New York: Basic Books, 1978.

[3] Alessi, L and Detken, C, (2011) "Quasi real time early warning indicators for costly asset price boom/bust cycles: A role for global liquidity" - European Journal of Political Economy 27.3 520-533.

[4] Borgy, V, Clerc, V, and J-P Renne (2009), "Asset-price boom-bust cycles and credit: what is the scope of macroprudential regulation?", Banque de France, Working Paper No 263.

[5] Borio, C, and Lowe, P (2002), "Asset prices, financial and monetary stability: exploring the nexus", BIS Working Papers No. 114.

[6] Drehmann, M, Borio, C, Gambacorta, L, Jimenez, G and Trucharte, C (2010), "Countercyclical capital buffers: exploring options", BIS Working Paper 317.

[7] Drehmann, M, Borio, C and Tsatsaronis, K (2011), "Anchoring countercyclical capital buffers: the role of credit aggregates", BIS Working Paper No 355.

[8] Schularick, M and Taylor A (2012), "Credit booms gone bust: Monetary policy, leverage cycles, and financial crises, 1870-2008", American Economic Review, no 102, pp 1029-61.

[9] Dell'Ariccia, G, Igan, D, Laeven, L, Tong, H, Bakker, B, Vandenbussche, J (2012), "Policies for Macrofinancial Stability: How to Deal with Credit Booms", IMF Staff Discussion Notes No.12/06.

[10] Mendoza, E and Terrones, M (2008), "An anatomy of credit booms: Evidence from macro aggregates and micro data", NBER Working Paper no. 14049. 